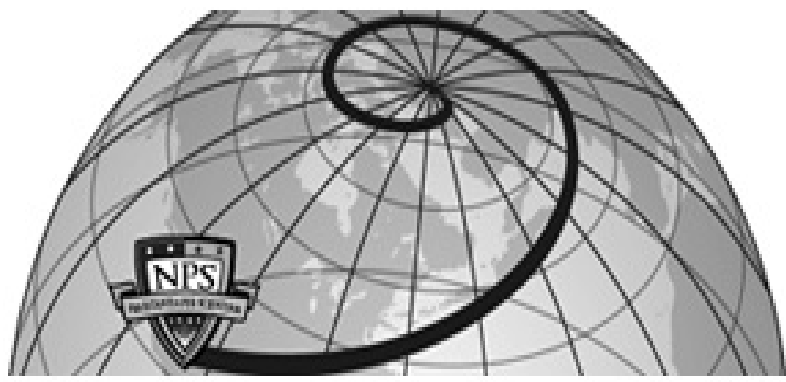

Calhoun: The NPS Institutional Archive DSpace Repository

1959

Precision $\mathrm{x}$-ray stress analysis of uranium and zirconium

House, Edward C.; Wooden, Bruce J.

Monterey, California: U.S. Naval Postgraduate School

http://hdl.handle.net/10945/14507

Downloaded from NPS Archive: Calhoun

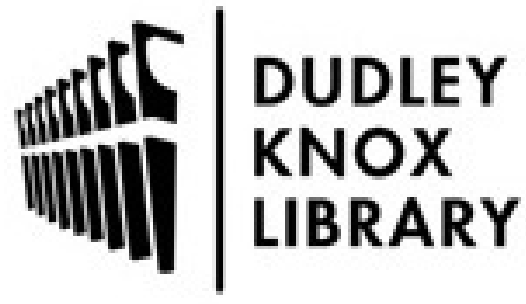

http://www.nps.edu/library
Calhoun is the Naval Postgraduate School's public access digital repository for research materials and institutional publications created by the NPS community. Calhoun is named for Professor of Mathematics Guy K. Calhoun, NPS's first appointed -- and published -- scholarly author.

Dudley Knox Library / Naval Postgraduate School 411 Dyer Road / 1 University Circle Monterey, California USA 93943 
NPS ARCHIVE 1959 HOUSE, E.

\title{
PRECISION X-RAY STRESS ANALYSIS OF URANIUM AND ZIRCONUUM
}

\author{
EDWARD C. HOUSE \\ AND \\ BRUCE 1. WOODEN
}


LIBRARY

U.S. NAYAL POSTGRADUATE SCHOO!

MOR..... C, ., ORNIA 






\section{PRECISION X-RAY STRESS ANALYSIS OF}

URANIUM AND ZIRCONIUM

by

Edward C. House

B. S., University of Kansas

(1953)

and

Bruce J. Wooden

B. S., U. S. Naval Academy

(1954)

Submitted to the Department of Naval Architecture and Marine Engineering on 25 May 1959 in partial fulfillment of the requirements for the Master of Science degree in Naval Architecture and Marine Engineering and the Professional degree, Naval Engineer.

Signature of Authors

Department of Naval

Architecture and

Marine Engineering

Certified by

Thesis Supervisor

Accepted by

Chairman, Department Committee on Graduate Students 
WPS AREATUS

$17=9$

Wicas

House 
ABS TRACT

\title{
PRECISION X-RAY STRESS ANALYSIS OF \\ URANIUM AND ZIRCONIUM
}

\author{
Edward C。House \\ Lieutenant, USN \\ and \\ Bruce J. Wooden \\ Lieutenant, USN
}

Submitted to the Department of Naval Architecture and Marine Engineering on 25 May 1959 in partial fulfillment of the requirements for the Master of Science degree in Naval Architecture and Marine Engineering and the Professional degree, Naval Engineer。 



\section{ABSTRACT}

The feasibility of using x-ray diffraction methods to measure residual stresses in uranium and zirconium (Zircalloy-2) was investigated. A precision method was developed for the determination of diffraction peak positions and the precision associated therewith. The statistical tables of Fisher and Yates were used to determine what order polynomial provided the best least squares fit within the known precision of the observed data. It was found that a second order polynomial provided an adequate regression. With the aid of a desk calculator, less than five minutes' calculation time is required to determine the peak position to a precision of $\pm 0.01^{\circ}$.

A General Electric XRD-3 Diffraction Unit was used in this investigation. The standard two-exposure method was employed in all stress measurements with the oblique position taken at $45^{\circ}$. Cobalt, copper, and chromium radiations were investigated in determining the best highangle lines to be employed. The stress constants were determined using annealed specimens of uranium and Zircalloy-2 stressed in bending. The stress was measured with two strain gages placed one on either side of the irradiated area.

The stress constant for uranium was determined to be $1308 \pm 110$ psi $/ 0.01^{\circ}$ shift in $\Delta 2 \theta$ for copper radiation on the (116) planes at $2 \theta=158.3^{\circ}$. The stress constant for Zircalloy-2 was determined to be $430 \pm 1 \mathrm{psi} / 0.01^{\circ}$ shift in $\Delta 2 \theta$ for chromium radiation on the (10.4) planés at $2 \theta=156.4^{\circ}$.

The surface stress distribution adjacent to the butt weld of two flat plates of Zircalloy-2 was measured. It was found that the weld produced a significant effect upon the stress distribution adjacent to the weld.

It is concluded that the expected precision as determined by statistical analysis can be attained using the method developed herein. It is recommended that a round robin specimen be sent to several stress analysis laboratories to fully verify this fact and to establish confidence in this method of residual stress measurement.

Thesis supervisor: Title:
Robert E。Ogilvie

Assistant Professor of Metallurgy 



\section{TABLE OF CONTENTS}

I. Introduction $\quad 1$

II. Procedure $\quad 4$

III. Results 11

IV. Discussion of Results 15

$\begin{array}{ll}\text { V. Conclusions and Recommendations } & 17\end{array}$

$\begin{array}{ll}\text { VI. Appendix } & 18\end{array}$

$\begin{array}{ll}\text { Section A } & 23\end{array}$

$\begin{array}{ll}\text { Section B } & 30\end{array}$

Section C 32 



\section{LIST OF ILLUSTRATIONS}

Figure I Calibration Specimen Mounted on the XRD-3 Goniometer 8

$\begin{array}{lr}\text { Figure II Welded Plate Mounted for Stress Analysis } & 10\end{array}$

Figure III Calibration Curve for Uranium 12

Figure IV Calibration Curve for Zircalloy-2 13

Figure V Plot of Welded Plate Surface Stress Distribution 14

Figure VI Diffraction Peaks for Uranium and Zircalloy-2 18 



\section{ACKNOWLEDGMENT}

The authors wish to express their sincere appreciation to Professor Robert E. Ogilvie who so generously offered his help during supervision of this thesis.

To Tom Flannagan the authors wish to express their sincere thanks for the help he so graciously gave throughout the period of this work。

Deepest appreciation is extended to Nuclear Metals, Incorporated, and $\mathbf{M}$ and $\mathbf{C}$ Nuclear, Incorporated, who made this work possible. 



\section{INTRODUCTION}

Since the work of Lester and Aborn (1) in 1926, the use of $x-r a y$ diffraction techniques to determine residual stresses has been considered feasible - at least from the theoretical point of view. Bragg's law as pertaining to diffraction of x-rays from a crystal may be stated as:

$$
\mathrm{n} \lambda=2 \mathrm{~d} \sin \theta
$$

where

$\mathrm{n}$ is an integer

$\lambda$ is the wavelength of the radiation

$d$ is the spacing between atomic planes in the crystal

$\theta$ is the angle of incidence between the $x-r a y$ beam and the atomic plane.

For plane stress as in the surface of a stressed specimen, classical theory of elasticity predicts that: 1

$$
\sigma=\frac{\Delta d}{d} \frac{E}{1+u} \frac{1}{\sin ^{2} \psi}
$$

where

$\Delta d$ is the difference in the lattice spacing of the (hkl) planes parallel to the surface and at an angle $\psi$ to the surface normal

$\sigma$ is the stress

$E$ is the modulus of elasticity

$u$ is Poisson's ratio

Combining the above two equations:

$$
\sigma=\left(\frac{E}{1+u}\right) \frac{\Delta \theta}{\sin ^{2} \psi \tan \theta}=(\mathrm{K})(\Delta \theta)
$$

where $\mathrm{K}$ is the stress constant.

1 For complete derivation see (2). 

Equation (3) indicates that the stress in the surface of a specimen is directly proportional to the difference between the peak position values of $\theta$ as observed in the normal and oblique observations. The direction of this stress is defined by the intersection of the plane containing the x-ray beam in the two observations with the surface of the material.

A great deal of work has been done in the past few years investigating mechanical failure of materials - particularly in attempting to correlate the material strength and fatigue endurance to the physical and metallurgical characteristics of a material. Most investigators (3), (4), (5) believe the residual surface stresses to be an important parameter in this regard。

Several methods have been devised to measure residual stresses. of these, only the x-ray diffraction method is non-destructive. Another advantage is that only the stresses in the very surface fibres are measured as compared to the integrating effect of the various mechanical dissection techniques (6). However, the xwray diffraction method has never become a generally accepted method of stress determination (6) be cause of the lack of precision in the reported results.

It is the firm belief of the authors that the method itself is quite reliable. It is rather the improper experimental approach to the problem by most investigators which has caused the difficulty。 since precision of the order of $0.01^{\circ}$ is desired in measuring diffraction peak 

positions, one must be extremely careful in the experimental procedure and, more important, in the treatment of the observed data. Precision is a mathematically defined concept (7) and one often overlooked or merely estimated roughly in research as well as in engineering work. With the exception of Ogilvie's method of least squares determination of the diffraction peak position (8), there is no evidence of an approach sufficiently careful to warrant the expected and assumed precision. It is little wonder that there has been a lack of precision and accuracy in the results reported using x-ray diffraction methods.

When dealing with statistical data, one must apply the well established principles of statistics in order to obtain the maximum correct information from the observed data. The observed counting rate of diffracted $x-r a y s$ is definitely statistical in nature as was verified by application of the Chi-squared test to a set of observed data. In experimental design it is appropriate to have the statistical precision limitations of the same order of magnitude or less than the inherent errors in the apparatus。 



\section{PROCEDURE}

A precision method of diffraction peak position determination was developed. 2 The regression method by orthagonal polynomials (9), (10), (1i) was applied to observed intensity data across the diffraction peaks chosen for subsequent stress evaluation。 65,536 counts were observed at each of seven equally spaced values of angle across the peak. Use of the Fisher and Yates tables (11) provides a quick method for determining the order of polynomial which should be fitted to best approximate the observed data. ${ }^{3}$ The criteria for fitting is the least squares fit which results in a mean square deviation of the same value as the variance of the observed data. It was found that a second order polynom ial was the appropriate function to be used. 4 The direct method of peak determination as recommended by ogilvie (8) was developed in terms of the orthagonal polynomials. This method in conjunction with the Fisher and Yates tables greatly simplifies this calculation for any number of points (up to 75 pointsi。 Once the peak has been ${ }^{\circ}$ counted, ${ }^{0}$ less than five minutes" calculation time is required by this method to determine the diffraction peak position from seven points. This least-squares method was used throughout this work.

Uranium and Zircalloy-2 specimens were irradiated with $x-$ radiation from cobalt, copper, and chromium in order to determine the appropriate 

diffraction lines to be observed. As high a $2 \theta$ value 5 as possible was chosen to get good precision. The reason for this may be seen as follows:

From Equation (3), for constant stress and $\psi$

$$
\Delta \theta \propto \tan \theta
$$

which shows that a high-angle line is most desirable for best precision. The lines chosen were:

$$
\begin{array}{lll}
\text { Uranium } & \text { Copper Radiation } 2 \theta=158.3^{\circ} & \text { (116) planes } \\
\text { Zircalloy-2 Chromium Radiation } 2 \theta=156.4^{\circ} & \text { (10.4) planes。 }
\end{array}
$$

A General Electric $\mathrm{XRD} \sim 3$ diffraction unit was used throughout this investigation. The slit arrangement, filtering, high voltage and current values were varied to determine the optimum arrangement. In general it was desired to obtain as high a counting rate as possible to yield ade quate precision in a reasonable time. No attempt was made to determine the background counting rate since no variation was to be expected over the region considered $\left(0.30^{\circ}\right)$. The final experimental arrangement chosen was:

$$
\begin{aligned}
& \text { Filter } \infty \text { none } \\
& \begin{array}{r}
\text { Divergence slit }-3^{\circ} \text { with solar baffles irradiating an } \\
\text { area } 6 \mathrm{~mm} \times 1 \mathrm{~cm} \text { on the specimens. }
\end{array} \\
& \text { Receiving slit }-0.1^{\circ} \text { (positioned on the focus circle) } 6 \\
& \text { High Voltage }-47.5 \mathrm{kv}
\end{aligned}
$$





$$
\begin{aligned}
& \text { Current } 16 \mathrm{ma} \\
& \text { Oblique Angle } \psi=45^{\circ} \\
& \text { Collimating Receiving slit } 0.3^{\circ}
\end{aligned}
$$

It was found necessary to allow an hour's warmmup time for the machine with the $\mathrm{x}$-ray tube on before a stable counting rate could be observed. 7 This is most important for precise work. An appreciable shift in the apparent peak position will result if the average intenw sity is changing during the period of time required to ${ }^{\circ}$ count ${ }^{\circ}$ a peak. Also, the diffraction unit must be carefully aligned prior to precise stress evaluations.

The stress calibration constants were determined by observing the change in $\Delta 2 \theta$ as the surface stress was varied known amounts. Specimens of uranium and Zircalloy- 2 were vacuum annealed at $500^{\circ} \mathrm{C}$ for 8 hours to remove any residual stresses caused by fabrication. Type A-7 SR4 strain gages were mounted on either side of the area to be irradiated. Each gage was read before and after each run, and the stress was calculated from the average strain value observed as measured with a type I Baldwin strain Indicator se 553470 . A Sanborn Twin Visa continuous strain recording system was used to verify that the strain remained constant throughout a run.

The specimens were stressed in a four $\propto$ point bending device, thereby assuring a constant stress over the irradiated area. This was 

verified experimentally by the strain gage measurements. The experimental setup is shown in Figure $I$, which shows the specimen in place and mounted on the goniometer of the diffraction unit. The alignment pedestal is shown in position for checking alignment of the specimen on the axis of the goniometer. Alignment of the specimen was checked before each run to within \pm 0.001 inches.

The data for each peak was taken as follows. A slow scan of the peak was made. The apparent maximum point of the peak was determined to the nearest $0.05^{\circ}$. The time for 16,384 counts was recorded for each of seven points $0.05^{\circ}$ apart centered about the estimated maximum value. Four separate counts across the peak were performed. This time sequence is more desirable than merely counting each point four times and then shifting to the next $2 \theta$ value, as any transient effects tend to be eliminated。

The geometrical correction factor due to any slight misalignment was taken to be the apparent $\Delta 2 \theta$ value for a standard silicon specimen and a powdered tungsten specimen at approximately the same $2 \theta$ angle as that used in the stress constant determination. Although this correction is relatively unimportant in evaluating the stress constant, $K_{\text {g }}$ it is of prime importance in absolute stress measurement. It was found appropriate to remevaluate this constant for each experimental setup. In order to verify the precision method developed, each author evaluated the stress constant on a different specimen。 

$-8=$

\section{FIGURE I}

Calibration Specimen Mounted

on the XRD-3 Goniometer 



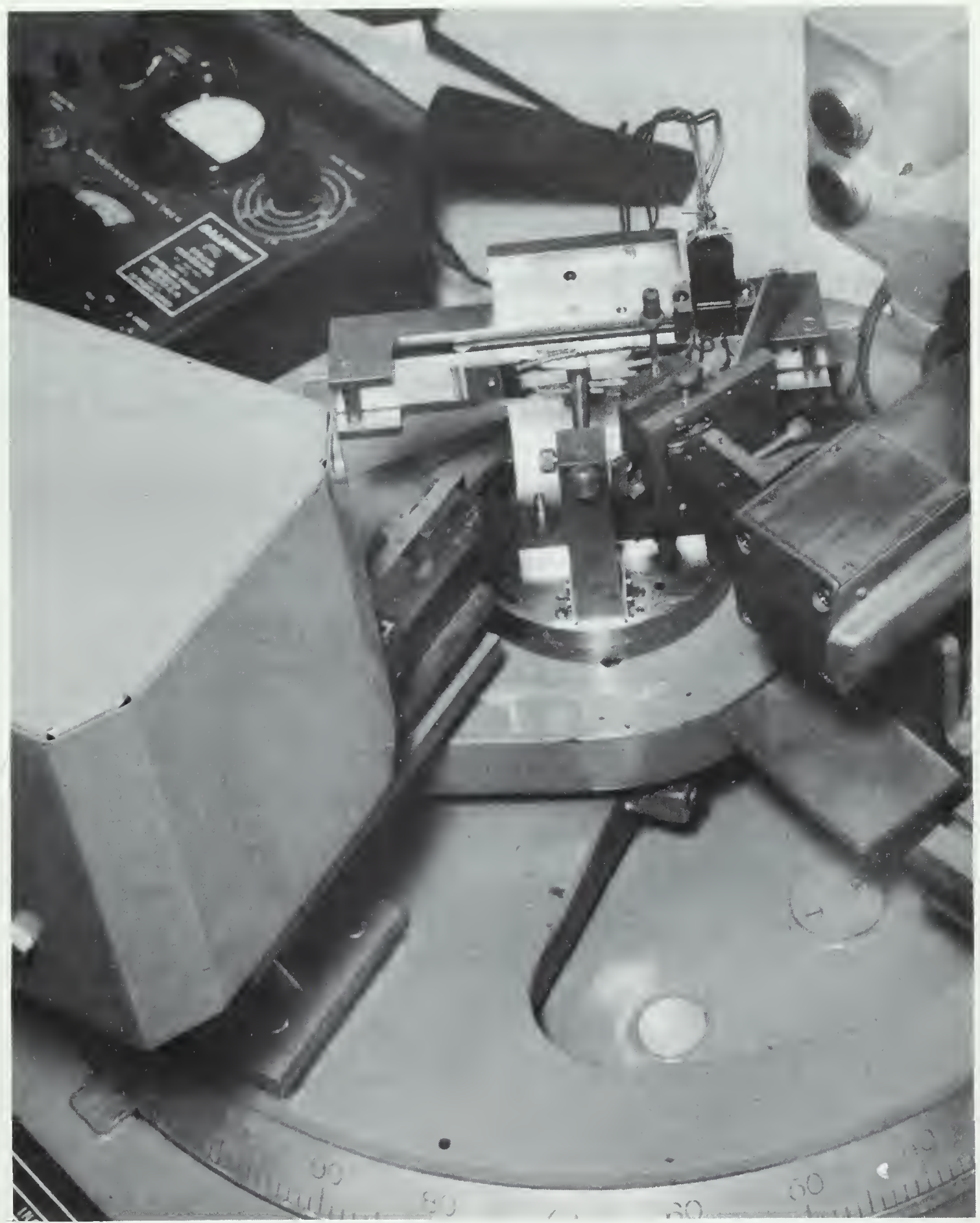

FIGURE I

Calibration Specimen Mounted on the XRD-3 Goniometer 

The weld-induced stress distribution adjacent to the tungsten electrode gas-shielded arc weld of two flat plates of Zircalloy-2 was measured. The $1^{\circ}$ divergence slit was used in this stress analysis, limiting the area examined to $3 \mathrm{~mm} \times 1 \mathrm{~cm}$ with the $1 \mathrm{~cm}$ side parallel to the weld. The welded specimen was mounted as shown in Figure II for stress evaluation. A stress pattern was determined as a function of distance from the center of the weld. 

$-10=$

FIGURE II

Welded Plate Mounted for Stress Analysis 



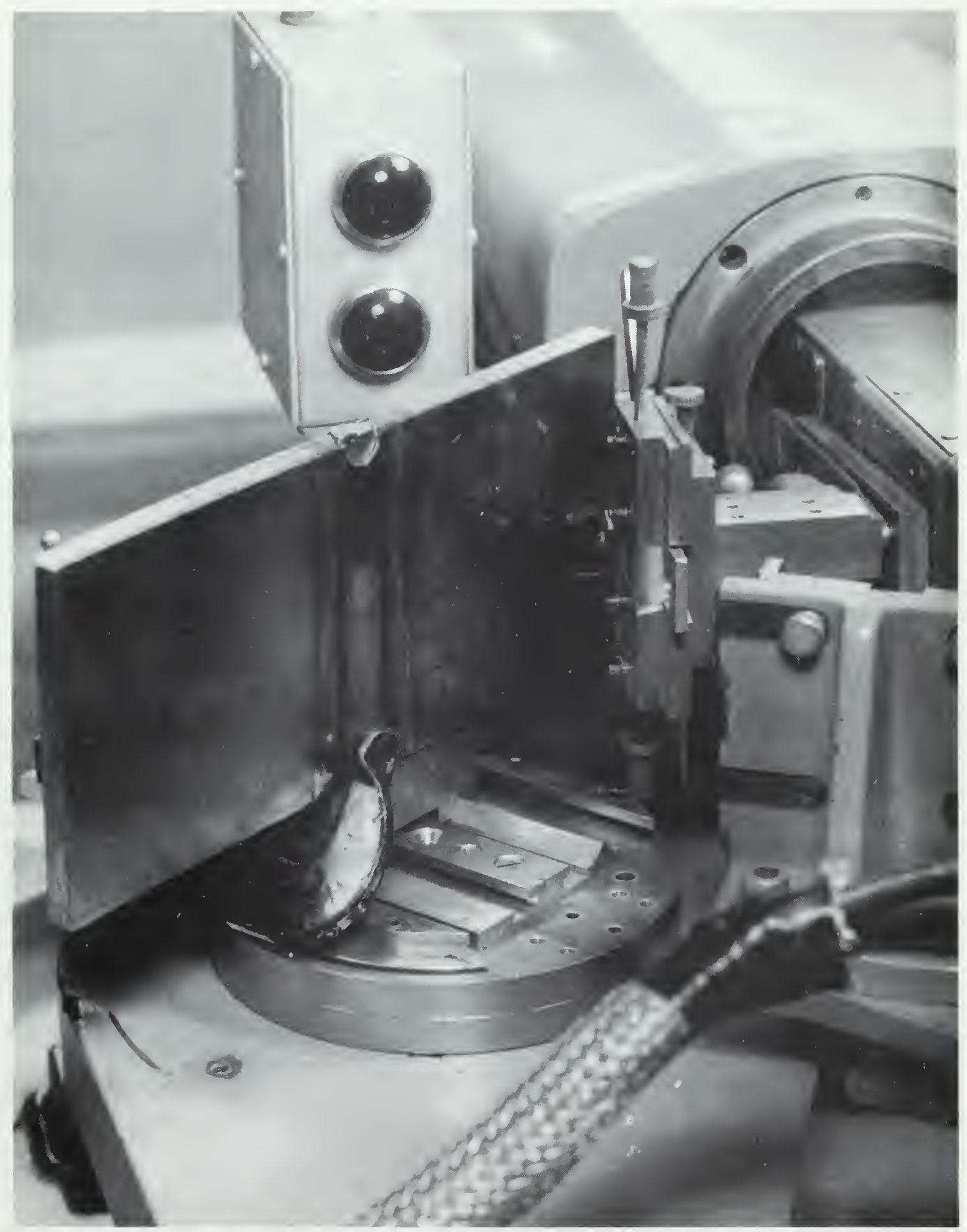

F IGURE II

Welded Plate Mounted for Stress Analysis 



\section{III。RESULTS}

The results for uranium are plotted in Figure III。 The stress calibration constant was evaluated as $1308 \pm 110 \mathrm{psi} / 0.01^{\circ}$ shift in $\Delta 2 \theta^{8}{ }^{8}$ This value was determined by a weighted least-squares corre⿻ lation with the predicted linear variation. The theoretical value was calculated to be $781 \mathrm{psi} / 0.01^{\circ}$ shift of $\Delta 2 \theta^{9}$ The precision limits quoted for the stress constant as well as those indicated on the plotted points in the $\Delta 2 \theta$ direction were calculated from the known precision of the observed data. The precision limits for stress were estimated from the $\pm 7.5 \mu$ in/in observed precision in reading strain. The standard law of propagation of errors was employed in these calculations. 10

The results for Zircalloy -2 are plotted in Figure IV. The stress calibration constant was evaluated as $430 \pm 1 \mathrm{psi} / 0.01^{\circ}$ shift in $\Delta 2 \theta$ using the same methods. 11 The theoretical value was calculated to be $377 \mathrm{psi} / 0.01^{\circ}$ shift $\Delta 2 \theta$ 。

Figure $V$ shows the variation of stress in the welded plate。 These stresses were measured in a direction normal to the direction of the weld along the centerline of the specimen.

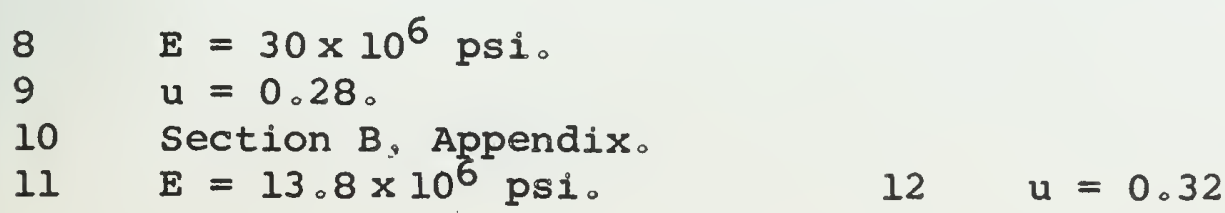





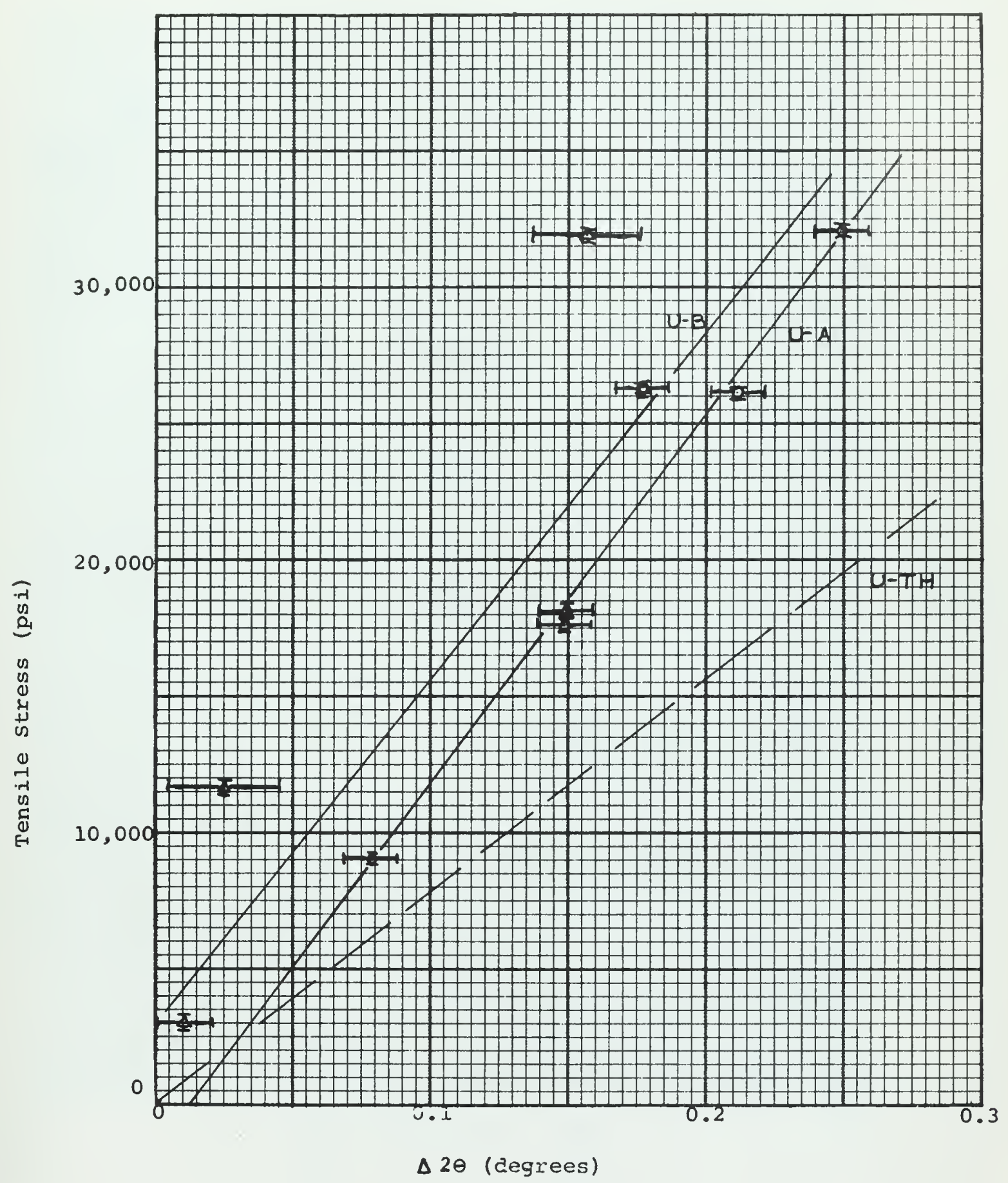

FIGURE III

Calibratior. Curve for Uranium 



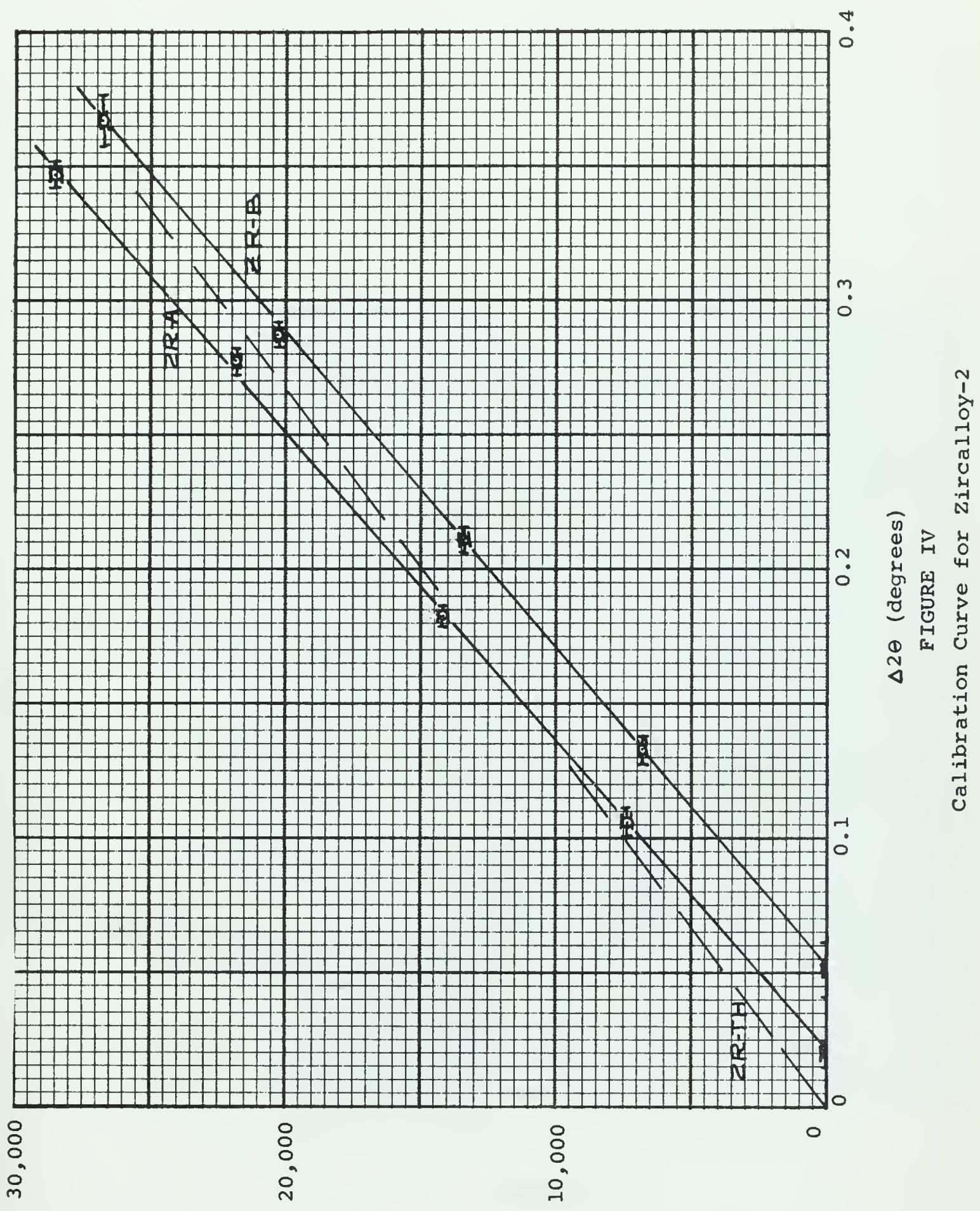

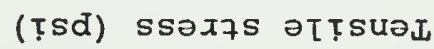





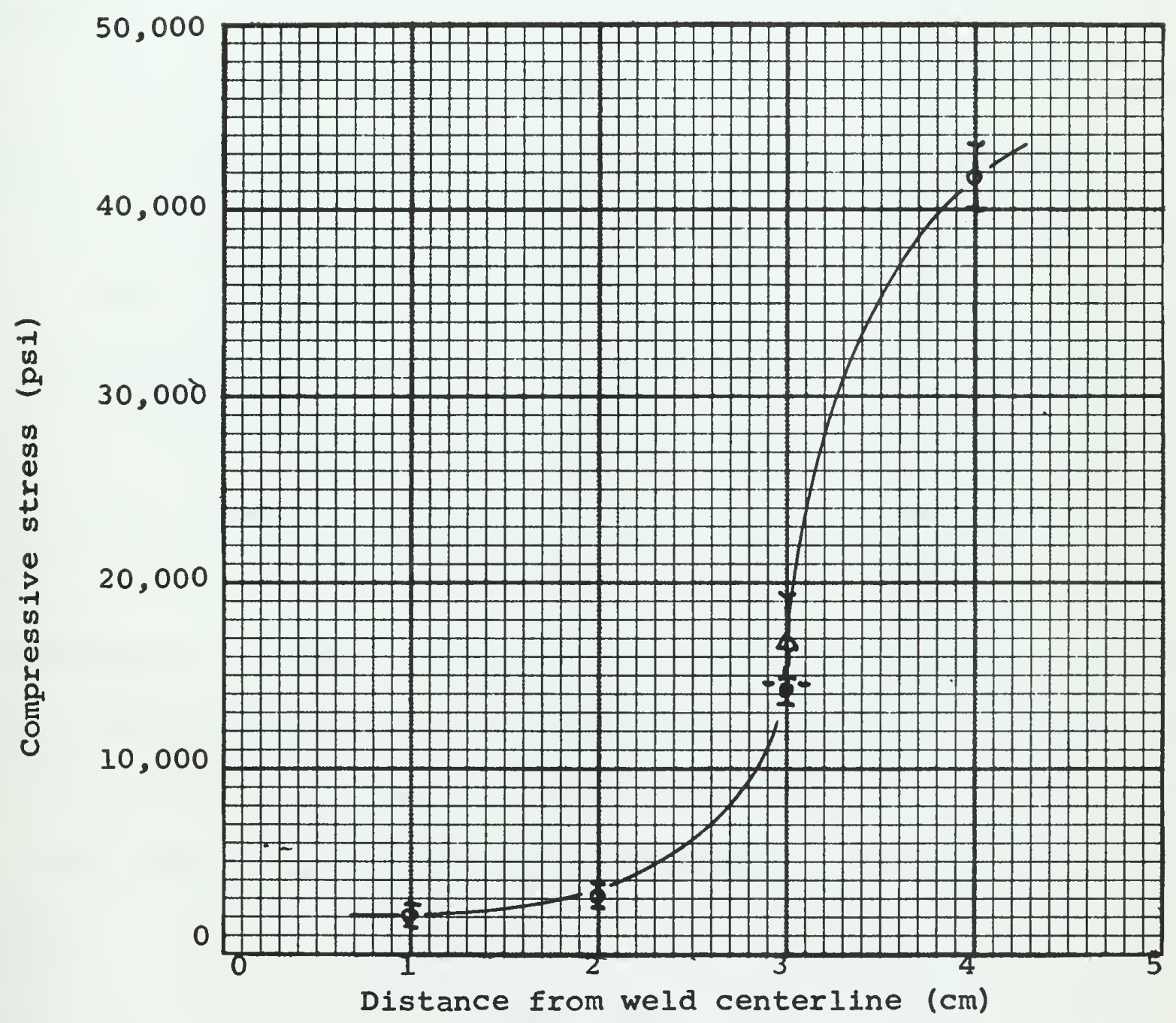

FIGURE V

Plot of Welded Plate Surface Stress Distribution 



\section{DISCUSSION OF RESULTS}

As shown in Figures III and IV, the results correlated quite well with the predicted linearity of stress as a function of $\Delta 2 \theta$. In each case the plotted curve does not pass exactly through the origin. The intercept of the curve with the ordinate axis indicates the residual stress in the specimen. This is to be expected, since it is extremely difficult to produce completely stress-free specimens. The deviation of the theoretical and experimentally determined values for the stress constants are probably due to the anisotropy of the material constants.

The correlation between the observed and calculated precision is excellent. The data points, with but one exception, lie well within two calculated standard deviations of the least squares fitted straight lines。

The precision limits of stress for uranium are greater than those for Zircalloy-2 because of the difference in the modulus of elasticity. The variation in the precision of $\Delta 2 \theta$ is due principally to peak broadening. This effect is included in the denominator term of the error equation. 13

It is interesting to note that even with the greater spread of data for the uranium $\rightarrow B$ specimen, the precision limits of the resultant stress constant were less than for the uranium-A specimen. Although

13 Error equation is derived in section $C$ of the Appendix. 

this result is not to be expected in every case, the additional information provided by the extra point for the uranium $-B$ specimen outweighed the comparative lack of precision for that specimen。

The observed surface stress distribution in the welded plate (Figure V) indicates that the plate was not fully annealed prior to welding. This is substantiated by two factors. First, broadened diffraction peaks were observed in the regions away from the weld, the condition normally present in an unannealed plastically deformed material. Second, large compression stresses, which are characteristic of rolled plate, were observed far removed from the weld. The observed stress pattern is presumed to be due to the combined effects of fabrication and welding。 



\section{CONCLUSIONS AND RECOMMENDATIONS}

It is concluded that with the proper experimental approach and statistical analysis of the observed data, the x-ray diffraction method for measuring residual stresses is indeed a practicable one. This fact is especially emphasized by the excellent results herein obtained using diffraction peaks that would hardly be considered sharp peaks, as shown in Figure VI. The excellent correlation between the results from the A and B specimens confirms the validity of the method.

It is recommended that this fact be firmly established by starting a round-robin specimen to various research and testing laboratories. This specimen should be accompanied by instructions for the method recommended herein in determining the residual stresses in the specimen. An alternate procedure would be to re-evaluate the data and/or remeasure the stresses in previously circulated specimens (6). In this way the true merit of the $x$-ray diffraction method would soon become apparent.

It is also recommended that further investigation be carried out in the fields of:-

1. a comparative investigation of higher intensity lower angle lines.

2. a comparative investigation of photographic techniques 。

3. a complete stress analysis of the weld-induced stress in a properly annealed specimen.

There are numerous possible applications of this technique in 

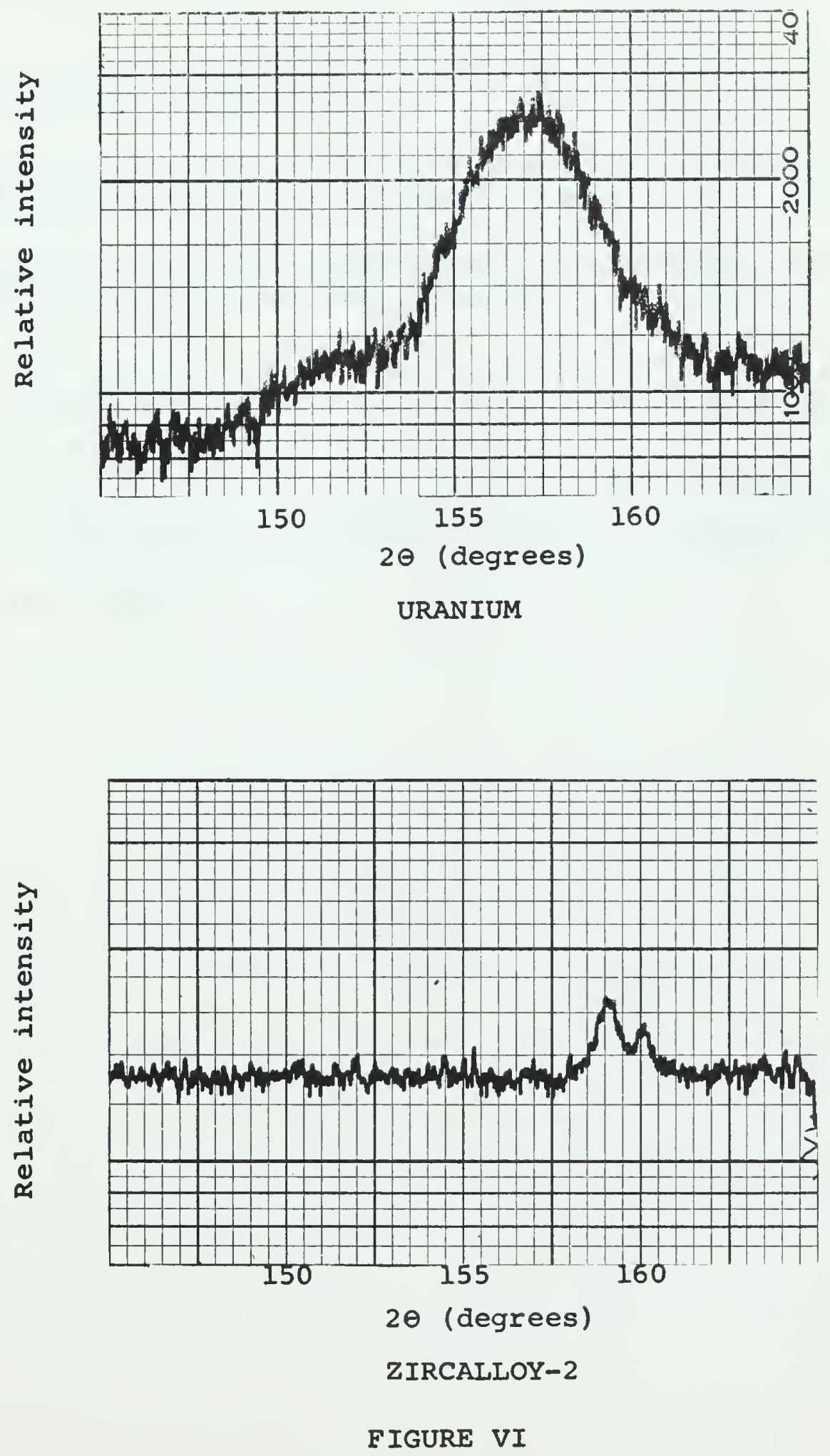

Diffraction Peaks for Uranium and Zircalloy-2 

the field of reactor design. Some of these would include:

1. Evaluation of stresses produced by local hot spots in Zircalloy -2 cladding.

2. Determination of the stresses induced by welding and fabrication techniques in fuel elements.

3. Determination of the appropriate heat treatments to properly relieve residual stresses。

The curvewitting and error propagation techniques described herein are perfectly general. They can and should be applied in any experimental investigation, in order to properly establish the precision of the results. 



\section{BIBLIOGRAPHY}

1. Lester and Aborn, ${ }^{10}$ Behavior Under Stress of the Iron Crystals in Steel, Army Ordnance vol。6, 1925-26.

2. Donachie, M。J。Jro, ${ }^{10}$ Lattice Strain and $\mathrm{X}=\mathrm{ray}$ Stress Measurement, ${ }^{\circ}$ Sc。D。"Thesis, M。I.T。, 1958。

3. "X-ray Measurement of Residual Stress in Hardened High Carbon Steel," by A。 L。Christenson and E。 S。 Rowland, Transactions ASM, 1952, p。638。

4. ${ }^{\circ} \mathrm{A}$ Simplified Procedure for Calculating Peak Position in Xmray Residual Stress Measurements on Hardened Steel, "by D。P. Koistinen and R。E. Marburger, ASM 1958 Preprint No。102。

5. Huang, T。Co, "Bibliography on Residual Stress," SP-125, SAE, May 1954。

6. "Evaluation of Methods for Measurement of Residual Stress, ${ }^{\text {" }}$ SAE General Information Report No.TR-147, Sept。1957.

7. Evans, R。D, The Atomic Nucleus, McGraw-Hill Book Co。 Inc。, New York, 1955, IV。

8. Ogilvie, R。E。, "Stress Measurement with the X-ray Spectrometer, " S。M。Thesis, M。I。T。, 1952。

9. Kendall, M。 Go, The Advanced Theory of Statistics, Vol。 I and II, Charles Griffin and Company, Limited, London, 1946.

10. Goulden, CoHo, Methods of Statistical Analysis, John Wiley and Sons, Inco, New York, 1956。

11. Fisher, R。A。 and Yates, $F \circ$ Statistical Tables for Biological, Agricultural, and Medical Research, Oliver and Boyd, London, 1953。

12. Worthing, $A \circ G$ o and Geffner, Jos Treatment of Experimental Data, John Wiley and Sons, New York, 1943. 

13. "Least Squares Fitting of Data by Means of Polynomials, ${ }^{\infty}$ by $R$ 。 $T$ 。 Birge, Rev。Mod。 Physics, 298 $=360$, 1947 .

14. Barrett, CoS。, Structure of Metals, McGraw-Hill Publishing Company, 1943。 

$-22=$

VI . APPENDIX 



\section{REGRESSION AND ERROR ANALYSIS}

\section{A. Regression Analysis}

Regression is the determination of the coefficients of an assumed mathematical expression purporting to represent the true means of an array of data. The selection of the regression equation may be left to the judgment of the analyst, in which case the simplest form producing adequate results is desired, or there may be physical laws which will govern the selection. Whatever form the regression takes it must be remembered that the methods presented here are only mathematical means to an end.

Historically, the name, regression, originated with Galton, who first applied the method to determine how a population could remain in dynamic equilibrium if the sons inherited the characteristics of the father. He found that the sons" deviation from the mean stature was less than the fathers" and consequently the sons "regressed" toward the mean。

Consider an array of data with $n$ columns and $m$ rows such that one of the variables may be taken as independent. The first and probably most useful relationship between the variables would be that they were linearly related or nearly so. The questions to be answered are: that if they are not exactly linearly related, what degree of approximation must be made to obtain such a relationship?, and, is the difference from linearity significant? Assuming $\mathrm{x}$ to be the independent variable, and 

$Y$ the dependent variable, the coefficients of the equation

$$
\mathrm{y}^{\prime}=\mathrm{ax}+\mathrm{b}
$$

are to be determined。 $y_{i j}$ is the variate in the $i$ th column and the $j$ th row. The average value of the $i$ th row is $y_{i}$,

$$
y_{i}=\frac{1}{m} \sum_{j=1}^{j=m} y_{i j} \text { 。 }
$$

For reasons which will become obvious it is easier to determine the coefficients of

$$
y^{\prime}=a(x-\bar{x})+b,
$$

where $\bar{x}$ in the usual notation

$$
\bar{x}=\frac{\sum_{1}^{n} x_{i}}{n} \text {. }
$$

An appeal is now made to the Principle of Least Squares upon the assumption that it will lead to the most probable values of the coefficients. Therefore the minimum of

$$
G(a, b)=\sum_{i}^{n}\left(y_{i}-y_{i}^{p}\right)^{2}
$$

is desired. Substitution of the assumed function yields

$$
G(a, b)=\sum_{1}^{n}\left[y_{i}-b-a\left(x_{i}-\bar{x}\right)\right]^{2} .
$$

The minimizing conditions are

$$
\frac{\partial G}{\partial b}=-2 \sum_{1}^{n}\left[y_{1}-b-a\left(x_{i}-\bar{x}\right)\right]=0
$$





$$
\frac{\partial G}{\partial a}=-2 \sum_{1}^{n}\left[y-b-a\left(x_{i}-\bar{x}\right)\right]\left(x_{i}-\bar{x}\right)=0
$$

which leads to

$$
\begin{aligned}
& \sum_{1}^{n} y_{i}=b n+a \sum_{i}^{n}\left(x_{i}-\bar{x}\right) \\
& \sum_{i}^{n}\left(x_{i}-\bar{x}\right) y_{i}=b \sum_{i}^{n}\left(x_{i}-\bar{x}\right)+a \sum_{I}^{n}\left(x_{i}-\bar{x}\right)^{2} .
\end{aligned}
$$

Since by definition

$$
\text { and } \quad \begin{aligned}
\sum_{1}^{n}\left(x_{i}-\bar{x}\right)=0 \\
b=\frac{\sum_{1}^{n} y_{i}}{n}=\bar{y} \\
a=\frac{\sum_{1}^{n}\left(x_{i}-\bar{x}\right) y_{i}}{\sum_{1}^{n}\left(x_{i}-\bar{x}\right)^{2}}
\end{aligned}
$$

with the resulting desired expression

$$
y^{8}-\bar{y}=(x-\bar{x}) \frac{\sum_{1}^{n}\left(x_{i}-\bar{x}\right) y_{i}}{\sum_{1}^{n}\left(x_{i}-\bar{x}\right)^{2}},
$$

which is defined as the regression of $y$ on $x$.

With the constants of the equation now determined the question of the justification of a linear regression may be undertaken. The usual approach is to separate the deviation of any variate from the mean into 

two parts, the deviation due to regression and the deviation from the regression. There follows

$$
\begin{aligned}
& \bar{y}-y_{i}=\bar{y}-y_{i}^{\prime}+y_{i}^{\prime}-y_{i} \\
& \sum_{1}^{n}\left(\bar{y}-y_{i}\right)^{2}=\sum_{i}^{n}\left[\left(\bar{y}-y_{i}^{\prime}\right)+\left(y_{i}^{\prime}-y_{i}\right)\right]^{2} \\
& =\sum_{i}^{n}\left(y_{i}^{\prime}-\bar{y}\right)^{2}+2 \sum_{i}^{n}\left(y_{i}^{\prime}-\bar{y}\right)\left(y_{i}-y_{i}^{\prime}\right)+\sum_{1}^{n}\left(y_{i}-y_{i}^{\prime}\right)^{2} \\
& \therefore \quad \sum_{1}^{n}\left(\bar{y}-y_{i}\right)^{2}=\sum_{i}^{n}\left(y_{i}^{i}-\bar{y}\right)^{2}+\sum_{i}^{n}\left(y_{i}-y_{i}^{\prime}\right)^{2}
\end{aligned}
$$

since

$$
\left.\sum_{1}^{n}\left(y_{1}^{i}-\bar{y}\right) \quad y_{i}-y_{i}^{8}\right)=0 .
$$

Thus the important result that the variance of the mean can be summed from the variance due to regression and the variance from the regression.* The variance from regression, (residual), is certainly a good measure of the justification of the linear regression as compared with some other assumed mathematical expression. Although there are no set rules it would seem inappropriate to select an expression of higher order if the average variance from regression is appreciably less than the average variance

* It is entirely likely at this stage that an estimate of the statistical significance of the regression is desired. This may be obtained since there are now available two separate estimates of the same variance with $\mathrm{n}_{1}$ and $\mathrm{n}_{2}$ degrees of freedom. The " $\mathrm{Z}$ " or its equivalent " $\mathrm{F}$ " test or the better known student's "t" test may be applied. 

of the means of the variates. Mathematically this may be expressed as:

$$
\frac{1}{n} \sum_{n}^{1}\left(y_{i}^{\prime}-y_{i}\right)^{2} \simeq \frac{1}{n} \sum_{n}^{1}\left(\delta_{y i}^{2}\right)
$$

where $\delta_{y i}{ }^{2}$ is the variance of the mean of the $i$ th column in the array. If linear regression is found to be unsuitable, a logical exten sion is to investigate polynomial regression. A straightforward approach would be to assume an equation of the type

$$
y=b_{0}+b_{1} x+b_{2} x^{2}+\ldots b_{n} x^{n}
$$

and proceed as before by taking partial derivatives and applying the minimizing conditions. A better approach, as will be seen, is to define a set of orthagonal polynomials

$$
z_{n}=a+a_{1} x+a_{2} x^{2}+a_{3} x^{3} \cdot+a_{n} x^{n}
$$

where

$$
\begin{aligned}
& \sum_{1}^{n} z_{n}=0: \\
& \sum_{1}^{n} z_{k}=0: \\
& \sum_{1}^{n} z_{k n} z_{n}=0, n \text {; } k \text {. }
\end{aligned}
$$

By this definition

$$
\begin{aligned}
& z_{1}=x \\
& z_{2}=\left(x^{2}-\frac{n^{2}-1}{12}\right)
\end{aligned}
$$





$$
\begin{aligned}
& z_{3}=\left(x^{3}-\frac{3 n^{2}-7}{20} x\right) \\
& z_{4}=\left[x^{4}-\frac{3 n^{2}-13}{14} x^{2}+\frac{3\left(n^{2}-1\right)\left(n^{2}-9\right)}{560}\right] .
\end{aligned}
$$

As an example consider fitting a second degree polynomial to the data. The assumed expression is

$$
\mathrm{Y}^{\prime}=\mathrm{A}_{0}+\mathrm{A}_{1} \mathrm{z}_{1}+\mathrm{A}_{2} \mathrm{z}_{2}
$$

The function to be minimized is:

$$
G\left(A_{0}, A_{1}, A_{2}\right)=\sum_{1}^{n}\left(y_{i}-y_{1}^{\prime}\right)^{2} .
$$

Upon substitution

$$
G\left(A_{0}, A_{1}, A_{2}\right)=\sum_{1}^{n}\left(y_{1}-A_{0}-A_{1} z_{1}-A_{2} z_{2}\right)^{2},
$$

and differentiation

$$
\begin{aligned}
& \frac{\partial G}{\partial A_{0}}=2 \sum_{1}^{n}\left[\left(y_{i}-A_{0}-A_{1} z_{1}-A_{2} z_{2}\right)(-1)\right]=0 \\
& \frac{\partial G}{\partial A_{1}}=2 \sum_{1}^{n}\left[\left(y_{i}-A_{0}-A_{1} z_{1}-A_{2} z_{2}\right)\left(-z_{1}\right)\right]=0 \\
& \frac{\partial G}{\partial A_{2}}=2 \sum_{1}^{n}\left[\left(y_{i}-A_{0}-A_{1} z_{1}-A_{2} z_{2}\right)\left(-z_{2}\right)\right]=0 \text { 。 }
\end{aligned}
$$

By equations (22), (23), and (24)

$$
\begin{gathered}
\sum_{1}^{n}\left(y_{i}-A\right)=0 \\
A=\frac{\sum_{i}^{n} y_{i}}{n}=\bar{y}
\end{gathered}
$$





$$
\begin{aligned}
& A_{1} \sum_{1}^{n} z_{1}^{2}=\sum_{1}^{n} z_{1} y_{i} \\
& A_{1}=\frac{\sum_{1}^{n} z_{1} y_{i}}{\sum_{1}^{n} z_{1}^{2}} \\
& A_{2} \sum_{1}^{n} z^{2}=\sum_{1}^{n} z_{2} y_{i}{ }^{2} \\
& A_{2}=\frac{\sum_{1}^{n} z_{2} y_{i}}{\sum_{1}^{n} z_{2}^{2}}
\end{aligned}
$$

Further generalization leads to

$$
A_{n}=\frac{\sum_{1}^{n} z_{n} y_{i}}{\sum_{1}^{n} z_{n}^{2}}
$$

As mentioned previously the advantage of the method can be readily seen, since the sums of the squares from regression are:

$$
\begin{aligned}
& \text { Linear : } A_{1} \sum Z_{1} y_{i} \\
& \text { Quadratic: } A_{1} \sum Z_{1} y_{i}+A_{2} \sum Z_{2} y_{i} \\
& \text { nth } \quad: A_{1} \sum Z_{1} Y_{i}+A_{2} \sum Z_{2} y_{i}+\ldots+A_{n} \sum Z_{n} y_{i}
\end{aligned}
$$

The sum of the squares from regression can be easily determined and the effect of each additional stage of fitting evaluated.

There still remains, however, the determination of the constants 

of the orthagonal polynomials. The advantage of using orthagonal polynomials in the general case, when unequally spaced and/or unequally weighted values of the variates exist, is difficult to justify in so far as numerical labor is concerned: but for equally spaced and weighted values, the coefficients of the polynomials may be determined once and for all, and tabulated, for a cardinal number spacing. Tables of the polynomials for orders up to and including the fifth degree for up to and including seventy-five points have been developed by Fisher and Yates. These tables also include values for computing the sums of squares necessary.

\section{B. Precision and Propagation of Errors}

Consider the problem of calculating the precision, or error, of a function made up of independently measured functions (i。e, empirical data) whose errors are known. Such a problem would be the calculation of the total resistance coefficient for a model, where the resistance, speed, and surface area cannot be exactly determined.

The required assumptions are:

a. Each quantity to be considered must be arrived at independently.

b. The errors in the measured quantities must be small.

c. Positive and negative errors must be equally probable。

Let the true values of the measured quantities be $x_{1}, x_{2}, x_{3}$, etc。 

These values are to be combined in some manner to give the desired function

$$
x=f\left(x_{1}, x_{2}, x_{3}, \ldots\right)
$$

Let the true errors, which are unknown, of the measured quantities, be $e_{1}, e_{2}, e_{3} \ldots$ etc. The unknown error in $\mathrm{x}$ will be $\mathrm{E}$. Then

$$
X+E=f\left(x_{1}+e_{1}, x_{2}+e_{2}, x_{3}+e_{3} \ldots\right) \text {. }
$$

By the required assumption (b) $e_{i} / x_{i}$ is much less than one, and a Taylor's Series Expansion of equation (44) may be made with only the first order terms retained.

$$
x+E-x=E=\left(\partial x / \partial x_{1}\right) e_{1}+\left(\partial x / \partial x_{2}\right) e_{2} \ldots
$$

By squaring both sides of equation (45)

$$
\begin{aligned}
E^{2} & =\left(\partial x / \partial x_{1}\right)^{2} e_{1}^{2}+\left(\partial x / \partial x_{2}\right)^{2} e_{2}^{2}+\ldots \\
& +\left(\partial x / \partial x_{1}\right)\left(\partial x / \partial x_{2}\right) e_{1} e_{2} \ldots
\end{aligned}
$$

where the terms contain the errors in the form $e_{i}$ and $e_{i} e_{k}$. Since (by assumption c) the errors are equally probable in a positive and negative sense, the cross product terms will tend to cancel out. Therefore, the desired result, which is commonly termed the Law of Propagation of Errors, is,

$$
E^{2}=\left(\partial x / \partial x_{1}\right)^{2} e_{1}^{2}+\left(\partial x / \partial x_{2}\right)^{2} e_{2}^{2}+\ldots \ldots
$$

The error $e$ of a value $x$ is usually encountered in the form

$$
x \pm e
$$

This implies that there is a $50 \%$ probability that the true value of $x$ lies bẹtween $x$ plus $e$ and $x$ minus $e$ 。 



\section{Example}

Consider, as an example, the intensity data from an x-ray diffraction peak from a zircalloy -2 specimen under stress。

TABLE I。

Xøray diffraction data

\begin{tabular}{|c|c|c|c|c|c|c|c|}
\hline$i \longrightarrow$ & 1 & 2 & 3 & 4 & 5 & 6 & 7 \\
\hline $2 \Theta \longrightarrow$ & $156.50^{\circ}$ & $156.55^{\circ}$ & $156.60^{\circ}$ & $156.65^{\circ}$ & $156.70^{\circ}$ & $156.75^{\circ}$ & $156.80^{\circ}$ \\
\hline \multirow{2}{*}{$\begin{array}{c}\text { Time for } \\
16,384\end{array}$} & 36.22 & 35.68 & 34.57 & 34.75 & 34.94 & 35.58 & 36.40 \\
\hline & 36.51 & 35.50 & 34.25 & 34.74 & 35.23 & 35.20 & 36.69 \\
\hline counts & 36.56 & 35.42 & 34.87 & 34.27 & 34.83 & 36.22 & 36.49 \\
\hline (in sec) & 36.91 & 35.64 & 35.34 & 34.69 & 34.36 & 35.71 & 36.26 \\
\hline $\mathrm{Y}_{\mathrm{i}} \longrightarrow$ & 36.55 & 35.56 & 35.01 & 34.61 & 34.84 & 35.68 & 36.46 \\
\hline
\end{tabular}

In this array $m=4$

$$
\mathrm{n}=7 \text { 。 }
$$

Taking $Z^{\prime}$ values $\left(Z^{\prime}=h Z^{\prime}\right)$ from the Fisher and Yates tables for $n=7$ : 

TABLE II。

Coefficients of the orthagonal polynomials for $n=7$

\begin{tabular}{|c|c|c|c|c|c|}
\hline$i$ & $\mathrm{Z}_{1}^{0}$ & $\mathrm{Z}_{2}$ & $\begin{array}{r}Z^{0} \\
\end{array}$ & $\begin{array}{l}Z^{\prime} \\
\end{array}$ & $\begin{array}{r}\mathrm{Z}^{8} \\
\end{array}$ \\
\hline 1 & -3 & 5 & -1 & 3 & -1 \\
\hline 2 & -2 & 0 & 1 & -7 & 4 \\
\hline 3 & -1 & -3 & 1 & 1 & -5 \\
\hline 4 & 0 & -4 & 0 & 6 & 0 \\
\hline 5 & 1 & -3 & -1 & 1 & 5 \\
\hline 6 & 2 & 0 & -1 & -7 & -4 \\
\hline 7 & 3 & 5 & 1 & 3 & 1 \\
\hline$\sum_{1}^{7}\left(z^{1}\right)^{2}$ & 28 & 84 & 6 & 154 & 84 \\
\hline$h$ & 1 & 1 & $1 / 6$ & $7 / 12$ & $7 / 20$ \\
\hline
\end{tabular}



TABLE III。

Calculation of variance

\begin{tabular}{|l|c|c|c|c|c|c|c|}
\hline$i$ & $y_{i}$ & $y_{i}^{2}$ & $z_{1}^{1} y_{i}$ & $z_{2}^{0} y_{i}$ & $z_{3}^{0} y_{i}$ & $z_{4}^{1} y_{i}$ & $z_{5}^{0} y_{i}$ \\
\hline 1 & 36.55 & 1335.9025 & -109.65 & +182.75 & -36.55 & +109.65 & -36.55 \\
2 & 35.56 & 1264.5136 & -71.12 & +0 & +35.56 & -248.92 & +142.24 \\
3 & 35.01 & 1225.7001 & -35.01 & -105.03 & +35.01 & +35.01 & -175.05 \\
4 & 34.61 & 1197.8521 & 0 & -138.44 & 0 & +207.66 & 0 \\
5 & 34.84 & 1213.8256 & 34.84 & -104.52 & -34.84 & +34.84 & +174.20 \\
6 & 35.68 & 1273.0624 & 71.36 & +0 & -35.68 & -249.76 & -142.72 \\
7 & 36.46 & 1329.3316 & 109.38 & +182.30 & +36.46 & +109.38 & +36.46 \\
\hline$\Sigma$ & 248.71 & 8840.1879 & -0.20 & +17.06 & -0.04 & -2.14 & -1.42 \\
\hline
\end{tabular}

$\bar{y}=\frac{\sum y_{i}}{n}=35.53$

$\overline{\mathrm{Y}}^{2}=12623809$ 

TABLE IV。

Analysis of variance

\begin{tabular}{|c|c|c|c|}
\hline Degree of Fit & Sum of Squares $\triangleq(S S)$ & Residual & Average \\
\hline & & $\sum\left(y_{i}\right)^{2}-\Sigma(s S)_{i}$ & Residual \\
\hline 0 & $n \bar{y}^{2}=8836.6663$ & 3.5216 & \\
\hline 1 & $\frac{\left[\Sigma\left(z_{i_{i}} y_{i}\right)\right]^{2}}{\Sigma\left(z_{i_{i}}\right)^{2}}=.0014$ & 3.5202 & 0.503 \\
\hline 2 & $\frac{\left[\sum\left(z_{2 i}^{\prime} y_{i}\right)\right]^{2}}{\sum\left(z_{2 i}^{i}\right)^{2}}=3.4648$ & 0.0554 & 0.008 \\
\hline 3 & $\frac{\left[\sum\left(z_{3 i}^{1} y_{i}\right)\right]^{2}}{\sum\left(z_{3 i}^{1}\right)^{2}}=.0003$ & 0.0551 & 0.008 \\
\hline 4 & $\frac{\left[\sum\left(z_{4 i}^{\prime} y_{i}\right)\right]^{2}}{\sum\left(z_{4 i}^{i}\right)^{2}}=.0297$ & 0.0254 & 0.0036 \\
\hline 5 & $\frac{\left[\sum\left(z_{5 i}^{\prime} y_{i}\right)\right]^{2}}{\sum\left(z_{5 i}^{\prime}\right)^{2}}=.0240$ & 0.0014 & 0.0002 \\
\hline
\end{tabular}



As discussed above, the residual, (variance from regression), is the required measure of goodness of fit. If a seventh degree equation had been chosen the residual would be zero, as the curve would pass exactly through each point.

However the precision (i.e., the variance) to which each $Y_{1}$ value is known is easily calculable. For counting a constant number of counts (s) in time ( $t$ ), the variance $\left(\delta^{2}\right)$ is given by:

$$
\delta^{2}=\frac{1}{m}\left(\bar{t}^{2} / s\right)
$$

(The variance of the mean of four counts is one-fourth the variance of any one。)** Therefore:

$$
\text { for } \quad \begin{aligned}
m & =4 \\
t & \simeq 35 \\
s & =16384 \\
\delta^{2} & =.019 \mathrm{sec}^{2}
\end{aligned}
$$

Thus it is seen that the second order equation is the appropriate regression to be employed.

The information that is desired is not specifically the regression equation but its maximum value which may be determined as follows:

$$
Y_{e}=A+B^{\prime} Z_{1}^{8}+C^{i} Z_{2}^{\prime} \text { (in the notation of Fisher and Yates.) }
$$

EVANS - pp。 756 and 798 . 

where

$$
\begin{aligned}
& B^{\prime}=\frac{\sum y_{i} z_{i_{i}}}{\sum\left(Z_{1 i}^{b}\right)^{2}} \\
& C^{1}=\frac{\sum y_{i} z_{2 j}^{j}}{\sum\left(z_{2 i}^{i}\right)^{2}} \\
& \frac{d y_{e}}{d x}=0=B^{\prime} \frac{d z_{1}}{d x}+C^{\prime} \frac{d z_{2}}{d x} \\
& z_{1}^{1}=h_{1} x \\
& z_{2}^{8}=h_{2}\left(x^{2}-\frac{n^{2}-1}{12}\right) \\
& \frac{d Z_{1}^{\prime}}{d x}=h_{1} \\
& \frac{d z_{2}^{\prime}}{d x}=2 \times h_{2} \\
& \therefore \quad x_{\max }=\frac{-B^{8} h_{1}}{C^{8} 2 h_{2}}=\frac{-\sum y_{i} z_{1 i}^{i}}{\sum y_{i}^{*} z_{2 i}^{q}} \frac{\sum\left(z_{2 i}^{i}\right)^{2}}{\sum\left(z_{1 i}^{i}\right)^{2}} \frac{1}{2 h_{2}}
\end{aligned}
$$

Determination of the precision:

$$
\begin{aligned}
& \text { Assuming } y_{i}=y_{i} \pm e_{i} \\
& x_{\max } \pm E=x_{\max } \pm\left[\left(\frac{d x}{d y_{i}} e_{i}\right)^{2}\right]^{1 / 2} \\
& \pi \equiv \frac{-\sum z_{i 1}^{2}}{\sum_{Z_{l i}^{2}}^{2}} \frac{h_{1}}{2 h_{2}} \quad \text { (is independent of } y \text { ) } \\
& \text { Assuming } e_{i}=e_{j}=\delta
\end{aligned}
$$





$$
\begin{aligned}
& E^{2}=\delta^{2} \Sigma\left(\frac{d x}{d y_{i}}\right)^{2} \\
& \frac{d x}{d y_{i}}=\pi \frac{\left[\left(\Sigma y_{i} z_{2 i}^{p}\right) z_{1 i}^{i}+\left(\Sigma y_{i} z_{1 i}^{\prime}\right) z_{2 i}^{i}\right.}{\left(\Sigma y_{1} z_{2 i}^{p}\right)^{2}} \\
& \sum\left(\frac{\partial x}{\partial y_{i}}\right)^{2}=\frac{\pi^{2}}{\left(\sum y_{i} z_{2 i}^{8}\right)^{4}} \sum\left[\left(\sum y_{1} z_{2 i}^{i}\right)^{2} z_{1 i}^{2}+\left(\sum y_{i} z_{1 i}^{i}\right)^{2} z_{2 i}^{8}\right] \\
& \sum Z_{1 i}^{1} Z_{2 i}^{1}=0 \\
& E=\frac{\pi \delta}{\left(\Sigma y_{i} z_{2 i}^{0}\right)^{2}}\left[\left(\Sigma y_{i} z_{2 i}^{i}\right)^{2} \Sigma\left(z_{1 i}^{0}\right)^{2}+\left(\Sigma y_{i} z_{1 i}^{0}\right)^{2} \sum\left(z_{2 i}^{0}\right)^{2}\right]^{1 / 2} \\
& E=\frac{\delta}{\left(\sum y_{i} z_{2 i}^{i}\right)^{2}}\left[\pi^{2} \sum\left(z_{1 i}^{i}\right)^{2}+x_{\max }^{2} \sum\left(z_{2 i}^{i}\right)^{2}\right]^{1 / 2}
\end{aligned}
$$

for $n=7$ from $F$ isher and Yates

$$
\begin{aligned}
& h_{1}=h_{2}=1 \\
& \sum\left(z_{1 i}^{\prime}\right)^{2}=28: \quad \sum\left(z_{2 i}^{i}\right)^{2}=84 \\
& \pi=\frac{84 \times 1}{28 \times 1 \times 2}=\frac{3}{2} \\
& E=\frac{\delta}{\left(\sum y_{i} z_{2 i}^{1}\right)^{2}}\left(\frac{9}{4} 28+x_{\max }^{2} 84\right)^{1 / 2}
\end{aligned}
$$


for the particular example

$$
\begin{aligned}
& x_{\max }=\frac{-(. .2)}{17.06} \frac{84}{28} \frac{1}{2}=.0176 \\
& \sigma=.137 \\
& E=\frac{.137}{(17.06)^{2}}\left[\frac{9}{4} \times 28+.0003 \times 84\right]^{\frac{1}{2}} \\
& =.00406
\end{aligned}
$$

In terms of spacing which is $.05^{\circ}$

$$
x_{\max }=.00088 \pm .000203^{\circ}
$$

This calculated error due to counting statistics is negligible as compared to the geometrical precision of the diffraction unit. The instruction manual for the diffraction unit quotes a precision value of $\pm 0.002^{\circ}$. Therefore, the final value of peak position is:

$$
\begin{aligned}
& 2 B=156.650+x_{\max } \\
& 28=156.651 \pm 0.002^{\circ}
\end{aligned}
$$







